\title{
Speech Perception Outcomes after Cochlear Implantation in Children with GJB2/DFNB1 associated Deafness
}

\author{
Marina Davcheva-Chakar ${ }^{1}$, Emilija Sukarova-Stefanovska ${ }^{2}$, Valentina Ivanovska ${ }^{1}$ \\ Vesna Lazarevska ${ }^{3}$, Ilija Filipche ${ }^{4}$, Beti Zafirovska ${ }^{5}$ \\ 'Department of Audiology, University ENT Clinic, Skopje, Republic of Macedonia \\ ${ }^{2}$ Research Center of Genetic Engineering and Biotechnology "Georgi D. Efremov", Skopje, Republic of Macedonia \\ ${ }^{3}$ Hearing and Speech Rehabilitation Center, Skopje, Republic of Macedonia \\ ${ }^{4}$ Macedonian Academy of Sciences and Arts, Skopje, Republic of Macedonia \\ ${ }^{5}$ Institute of Epidemiology, Medical Faculty, Skopje, Republic of Macedonia
}

Background: Cochlear implants (CI) for the rehabilitation of patients with profound or total bilateral sensorineural hypoacusis represent the initial use of electrical fields to provide audibility in cases where the use of sound amplifiers does not provide satisfactory results.

Aims: To compare speech perception performance after cochlear implantation in children with connexin 26-associated deafness with that of a control group of children with deafness of unknown etiology.

Study Design: Retrospective comparative study.

Methods: During the period from 2006 to , cochlear implantation was performed on 26 children. Eighteen of these children had undergone genetic tests for mutation of the Gap Junction Protein Beta 2 (GJB2) gene. Bi-allelic GJB2 mutations were confirmed in 7 out of 18 examined children. In order to confirm whether genetic factors have influence on speech perception after cochlear implantation, we compared the post-implantation speech performance of seven children with mutations of the GBJ2 (connexin 26) gene with seven other children who had the wild type version of this particular gene.
The latter were carefully matched according to the age at cochlear implantation. Speech perception performance was measured before cochlear implantation, and one and two years after implantation. All the patients were arranged in line with the appropriate speech perception category (SPC). Non-parametric tests, Friedman ANOVA and Mann-Whitney's U test were used for statistical analysis.

Results: Both groups showed similar improvements in speech perception scores after cochlear implantation. Statistical analysis did not confirm significant differences between the groups 12 and 24 months after cochlear implantation.

Conclusion: The results obtained in this study showed an absence of apparent distinctions in the scores of speech perception between the two examined groups and therefore might have significant implications in selecting prognostic indicators of speech perception following cochlear implantation. (Balkan Med J 2014;31:60-63).

Key Words: Cochlear implantation, connexin 26, deafness, GJB2, speech perception
Hearing loss is a prevalent human sensory defect. There are many people in the world who suffer from hearing impairment. According to the Macedonian Association of the Deaf and Hard of Hearing, there are 6000 deaf people in the Republic of Macedonia. The incidence of congenital hearing impairment is at least 1 child in every 1000 born, and an additional 1 child in 1000 progressively develops deafness $(1,2)$.

Several environmental and genetic factors are causes of hearing loss. At least $50 \%$ of congenital hearing impairment has a genetic origin (3). Late onset of hearing loss can also be caused by genetic defects. Approximately $70 \%$ of genetic cases are non-syndromic, where deafness is the only clinical manifestation. Non-syndromic hearing impairment is further categorized by the mode of inheritance. Autosomal recessive inheritance is found in $80 \%$ of cases, while approximately
$20 \%$ are inherited in an autosomal dominant, $\mathrm{X}$-linked $(2 \%$ to $5 \%$ ), or mitochondrial (1\%) mode. The genetic basis of hearing loss is complex. It has been shown that more than 100 loci are involved in hearing loss (4). Despite enormous genetic heterogeneity, mutation in the Deafness Autosomal Recessive 1-B (DFNB1) locus containing the Gap Junction Protein Beta 2 (GBJ2) gene (13q12.11) is the predominant cause of autosomal recessive non-syndromic hearing loss. DFBN1 is generally characterized by prelingual deafness. The GBJ2 gene encodes for connexin 26 (Cx26), which is a gap junction protein responsible for potassium transport and ion homeostasis. Several recurrent mutations have been found in GBJ2 (35delG, $167 \mathrm{delT}$, and $235 \mathrm{delC}$ ), with specific prevalence in different ethnic groups (5-8). Molecular testing for GBJ2 has become the standard of evaluation of patients with non-syndromic 
impairment of unknown etiologies due to the high incidence of GBJ2 mutations. Studies on mutations in GJB2 in 120 persons with prelingual non-syndromic deafness in the Republic of Macedonia determined a prevalence of $25.8 \%$, with $35 \mathrm{delG}$ as the most frequent variation found in $68.2 \%$ of mutated chromosomes, followed by W24X (18.2\%), V371(9.1\%), and R127H (4.5\%) (9, 10).

One rehabilitation option for patients with severe to profound hearing loss is cochlear implantation. However, the performance of cochlear implants is very inconsistent and depends on many factors, such as the age of implantation, amount of residual hearing, and mode of communication. These factors can contribute to speech perception abilities but explain less than $50 \%$ of the variance in the results (11-13). The general opinion is that speech perception performance after cochlear implantation might be poorer due to primary reasons including neural or central damage of the auditory system, rather than causes primarily affecting the hair cells (e.g. hereditary non-syndromic deafness) such as connexin 26 mutation deafness $(12,13)$.

The aim of this study was to compare the speech perception performance after cochlear implantation in children with connexin 26-associated deafness with other children carrying the wild type connexin 26 gene.

\section{MATERIAL AND METHODS}

\section{Subjects and selection criteria}

In the period from 2006-2012 cochlear implantation was undertaken in 30 children at the University Ear, Nose and Throat Clinic in Skopje, Republic of Macedonia. Each of them had information consent. This study was approved by Ethical Comitee of the Medical Faculty in Skopje.

\section{Audiological evaluation}

All patients underwent audiometric examination using ageappropriate methods: pure tone audiometry, auditory brain-stem responses $(\mathrm{ABR})$, otoacoustic emissions and tympanometry (Audiometar CA-540, Octavus BERA, ILO 88 Hortman Otoacoustic Emissions, Tympanometar 87). The examinations were carried out at the Audiology Department of the University ENT Clinic, Skopje, R. Macedonia. All patients were diagnosed with profound hearing loss at 1.5 to 2.6 years of age and were implanted at 2.9 to 5.6 years of age.

All of the patients underwent a battery of cognitive, neurological and psychological tests consisted of: body mass and primitive reflexes assessment, motility assessment according to the corrected gestational age, and developmental assessment according BagleGriffiths developmental scales for 0-2 years and 2-7 years. No evidence of additional impairments or handicaps was found in either group. High-resolution CT imaging showed that there were no inner ear anomalies.

\section{Molecular genetic analysis}

Eighteen patients underwent genetic analysis at the Research Center of Genetic Engineering and Biotechnology "Georgi D. Efremov", Skopje, R. Macedonia. Written information consent was obtained from all participants or parents in the case of minors. DNA from 18 patients was extracted according to the standard phenol/ chloroform extraction ethanol precipitation procedure. The coding region of the gene was amplified in two separate PCR assays and subsequently sequenced using the Big Dye v 1.1 sequencing kit and electrophoresis on an ABI 3130 apparatus (Applied Bio systems). Of these, seven patients had bi-allelic GJB2 mutations that were the underlying cause of hearing impairment. Two patients had mono-allelic GJB2 mutations and the remaining nine patients had wild type alleles. Patients with mono-allelic GJB2 mutations were excluded from this investigation since the genetic origin of the deafness could not be explicitly confirmed.

Based on the genetic results, patients in this study were classified into two groups: seven patients with DFNB1 deafness (when biallelic mutations for GJB2 were detected ) and seven patients of the total of nine that served as a control group with no DFNB1 deafness (when no mutations were identified). The control patients were carefully matched according to the age of receipt of the cochlear implant.

\section{Speech perception evaluation}

Speech perception tests were performed by speech pathologists at the Hearing and Speech Rehabilitation Center, Skopje, R. Macedonia. The IT-MAIS test for preverbal children and tests for early speech perception were used. Perception categories were assigned to results appropriate to the speech perception category (SPC), as described by Moog and Geers (14). The scale with six levels includes categories where 0 means there is no detection, 1 stands for detection only, 2 for pattern perception, 3 for inconsistent closed-set word recognition and multiple spectral differences, 4 for consistent closed-set word recognition of vowels, 5 for consistent closed-set word recognition of consonants and 6 for open-set word recognition.

All tests were performed at the $70 \mathrm{~dB}$ sound pressure level via live voice, at a distance of one meter between the speaker/speech pathologist and the listener/examinee. Speech perception ability was measured before cochlear implantation, and 12 and 24 months after surgery. Statistical analysis was performed by the non-parametric Friedman ANOVA test and Mann-Whitney's U test.

\section{RESULTS}

The follow-up tests showed no differences between the two groups in terms of the mean age of implantation and duration of cochlear implant use. Communication mode and pure tone average before implantation $(\mathrm{dB})$ were found to be similar between the two groups. Table 1 gives the background data of two groups (DFNB1 group and control - non DFNB1 group).

Eighteen cochlear implanted patients underwent genetic examination. As shown in Table 1, seven patients who had bi-allelic DFNB1 mutations and seven patients who had wild type alleles of this particular gene were analyzed. 
Statistical analysis using non-parametric Friedman ANOVA test showed significantly greater differences in speech perception scores during the analyzed period before implantation, and 12 and 24 months after cochlear implantation for the DFNB1group $(\mathrm{p}=0.0009)$ and for the non-DFNB1 group $(\mathrm{p}=0.001)$. The results show that children who obtained cochlear implants demonstrated a rapid improvement in hearing abilities in the first year of device implantation as well as after the second year.

The mean SPC for DFNB1 patients was $3.29 \pm 0.3$ and $3.25 \pm 0.33$ for non-DFNB1 patients 12 months after cochlear implantation. After 24 months, the mean SPC for DFNB1 and non-DFNB1 patients was $4.86 \pm 0.38$ and $4.7 \pm 0.47$, respectively. Statistical analysis using the non-parametric Mann-Whitney's $U$ test did not confirm substantial variations between the groups 12 months after cochlear implantation $(\mathrm{p}=0.56)$ and 24 months after cochlear implantation $(\mathrm{p}=0.37)$. These results are illustrated in Figure 1.

\section{DISCUSSION}

According to some authors, many different factors influence the evaluation of speech perception outcomes in cochlear implanted children. A recent systematic pediatric cochlear implantation review demonstrated only three factors that sustained critical analysis. These were: late age of implantation, inner ear malformations and meningitis. In this review, connexin 26 (GJB2) mutations had a negligible impact (14).

Other authors have considered that the existence of biallelic GJB2 mutations does not rule out non-hearing related disorders that can affect speech, language and learning. They concluded that other conditions could directly affect pre-implant evaluation and post-implant function, and that all children should have a comprehensive assessment of development and behavior, regardless of the etiology of hearing loss (15).

The aim of this study was to compare speech perception outcomes after cochlear implantation in children with GJB2/ DFNB1 associated deafness without other comorbid conditions to children with deafness of unknown etiology and to determine the impact of this mutation on speech perception outcomes. The results show that cochlear implantation is effective in the development of speech perception after cochlear implantation in GJB2-related deafness to a similar extent as in deafness due to unknown etiology. These findings are in agreement with findings obtained by other authors $(4,13,15-22)$. A recent long term follow-up of cochlear implantation in children with GBJ2-related deafness in Japan showed similar developments in speech performance in comparison with hearing loss due to other etiologies (23).

Some studies have shown that children with the connexin 26 mutation had better speech perception outcomes after co-
TABLE 1. Description of groups and genotypes

\begin{tabular}{lcc}
\hline Variable & $\begin{array}{c}\text { DFNB1 } \\
\text { group (n=7) }\end{array}$ & $\begin{array}{c}\text { Non-DFNB1 } \\
\text { group (n=7) }\end{array}$ \\
\hline Age at implantation in years, & $4.36 \pm 1.1$ & $4.14 \pm 1.2$ \\
mean (range) & $(2.5-5.6)$ & $(2.9-5.6)$ \\
Mode of communication & Oral & Oral \\
Pure tone average before implantation & $115 \mathrm{~dB} \mathrm{HL}$ & $110 \mathrm{~dB} \mathrm{HL}$ \\
Speech perception category after 24 mounts & $4.86 \pm 0.38$ & $4.7 \pm 0.47$ \\
Mutations identified in GJB2 gene in & 35 delG/35 delG & None \\
cochlear implanted patients & $(4$ patients) & \\
& Trp24X/Trp24X & None \\
& (3 patients) & \\
\hline
\end{tabular}

DFNB1: deafness autosomal recessive 1-B; GBJ2: gap junction protein beta 2

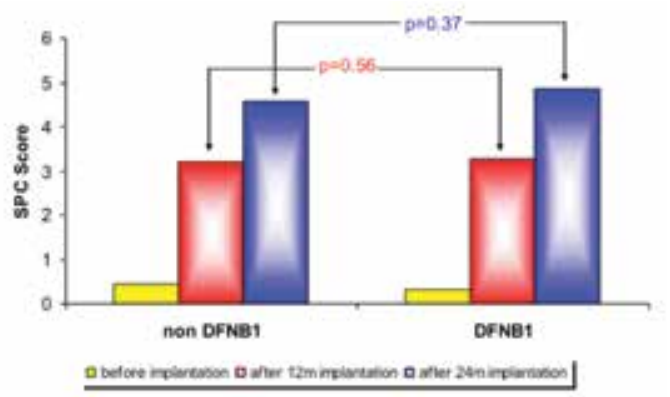

FIG. 1. Speech perception testing was performed according to the classification described by Geers and Moog (14) before and 12 and 24 mounts after cochlear implantation

chlear implantation and greater benefits in language expression tests than children with deafness of unknown etiology (24-26). A recent study of Portuguese children with cochlear implants showed that DFNB1 status is significantly associated to higher oral performance scores, i.e. $6 \%$ better than individuals without DFNB1-associated deafness (27). These different findings might be a result of the use of different tests for evaluating speech perception performance, insufficient follow-up after cochlear implantation or different criteria for inclusion or exclusion of children during the evaluation of speech perception.

We consider that future analyses are necessary, including a large number of implanted patients in whom other confounding factors are precluded. Our findings did not confirm significant differences regarding speech perception performance after cochlear implantation in children with connexin 26-associated deafness with that of a control group of children with deafness of unknown etiology. We consider that the information from this study will have great influence on the selection of predictive indicators of speech perception outcomes following cochlear implantation.

Ethics Committee Approval: Ethics committee approval was received for this study from the ethics committee of the Medical Faculty in Skopje. 
Informed Consent: Written informed consent was obtained from patients who participated in this study.

Peer-review: Externally peer-reviewed.

Author contributions: Concept - M.D-C., E.S-S.; Supervision - I.F.; Materials M.D-C., E.S.S., V.L., V.I.; Data Collection\&/or Processing - B.Z., V.I.; Analysis\&/or Interpretation - M.D-C., E.S-S., V.I.; Literature Search - M.D-C., E.S-S., V.L., V.I.; Writing - M.D-C., E.S-S., V.I.; Critical Reviews - I.F.

Conflict of Interest: No conflict of interest was declared by the authors.

Financial Disclosure: The authors declared that this study has received no financial support.

\section{REFERENCES}

1. Morton NE. Genetic epidemiology of hearing impairment. Ann NY Acad Sci 1991;630:16-31. [CrossRef]

2. Mason JA, Herrmann KR. Universal hearing screening by automated auditory brainstem response measurement. Pediatrics 1998;101:221-8. [CrossRef]

3. Van Camp G, Willems PJ, Smith RJ. Non-syndromic hearing impairment: unparalleled heterogeneity. Am J Hum Genet 1997;60:758-64.

4. Van Camp, Smith RJH. Hereditary Hearing Loss. Available from: http:// webhost.ua.ac.be/hhh/

5. Zelenate L, Gasparini P, Estivill X, Melchionda S, D’Agruma I, Govea $\mathrm{N}$, et al. Connexin 26 mutations associated with the common form of non-syndromic neurosensory autosomal recessive deafness (DFNB1) in Mediterranean. Hum Mol Gent 1997;6:1605-9. [CrossRef]

6. Cohn ES, Kelley PM. Clinical phenotype and mutations in connexin 26 (DFNB1/GJB2), the most common cause of childhood hearing loss. $\mathrm{Am}$ J Genet 1999;89:130-6. [CrossRef]

7. Estivill X, Fortina P, Surrey S, Rabionet R, Meichionda S, D'Agruma $\mathrm{L}$, et al. Connexin-26 mutations in sporadic and inherited sensorineural hearing deafness. Lancet 1998;351:394-8. [CrossRef]

8. Schrijver I. Hereditary Non-Syndromic Sensorineural Hearing Loss. $J$ Mol Diagn 2004;6:275-84. [CrossRef]

9. Sukarova-Stefanovska E, Momirovska A, Davcheva-Chakar M, Efremov G. GJB2 mutation in non-syndromic hearing loss in the Republic of Macedonia. BJMG 2009;12:11-6.

10. Sukarova-Stefanovska E, Cakar M, Filipce I, Plaseska-Karanfilska D. Genetics of non-syndromic hearing loss in Republic of Macedonia. $B J M G$ 2012;Suppl 15:57-9.

11. Clark GM. Cochlear implants. Bologna: Monduzzi Editore, 1977.

12. Francis HW, Pulsifer MB, Chinnici J, Nutt R, Venick HS, Yeagle JD, et al. Effects of central nervous system residua on cochlear implant results in children deafened by meningitis. Arch Otolaryngol Head Neck Surg 2004;130:604-11. [CrossRef]

13. Taitelbaum-Swead R, Brownstein Z, Muchnik C, Kishon-Rabin L, Kronenberg J, Megirov L, et al. Connexin associated deafness and speech perception after cochlear implantation. Arch Otolaryngol Head Neck Surg 2006;132:495-500. [CrossRef]

14. Black J, Hickson L, Black B, Perry C. Prognostic indicators in pediatric cochlear implant surgery: a systematic literature review. Cochlear implans Int 2011;12:67-93. [CrossRef]

15. Wiley S, Choo D, Meinzen-Deer J, Hilbert L, Greinwald J. GJB2 mutations and additional disabilities in a pediatric cochlear Implant population. Int J Pediatr Otorhinolaryngol 2006;70:493-500. [CrossRef]

16. Geers AE, Moog JS. Predicting spoken language acquisition of profoundly hearing -impaired children. J Speech Hear Disorders 1987;52:84-94.

17. Dahl HH, Wake M, Sarant J, Poulakis, Siemering K, Blamey P. Language and Speech perception outcomes in hearing -impaired children with and without connexin 26 mutations. Audiol Neurootol 2003;8:263-8. [CrossRef]

18. Cullen RD, Buchman CA, Brown CJ, Copeland BJ, Zdanski C, Pillsbury $\mathrm{HC} 3^{\text {rd }}$, et al. Cochlear implantation for children with GJB2related deafness. Laryngoscope 2004;114:1415-9. [CrossRef]

19. Dalamon V, Lotersztein V, Lipovsek M, Beheran A, Mondino ME, Diamante F, et al. Performance of the speech perception after cochlear implantation in DFNB1 patients. Acta Otolaryngol 2009;129:395-8. [CrossRef]

20. Wrobel M, Magierska-Krzyszton M, Szyfter K, Mietkiewska D, Szyfter W, Rydzanicz M, et al. Comparison of rehabilitation results in deaf patients with and without genetically related hearing loss. Cochlear Implants Int 2008;9:132-42. [CrossRef]

21. Bauer PW, Geers AE, Brenner C, Moog JS, Smith RJ. The Effect of GJB2 allele variants on performance after cochlear implantation. Laryngoscope 2003;113:2135-40. [CrossRef]

22. Liu J, Yu F, Dai P, Han DY, Yang SM, Wang GJ, et al. Mutation of Gap junction protein beta 2 gene and treatment outcome of cochlear implantation in Cochlear implantation recipients. Zhonghua Yi Xue Za Zhi 2009;89:433-7.

23. Yoshida H, Takahashi H, Kanda Y, Usami S. Long term speech perception after cochlear implant in pediatric patients with GJB2 mutations. Auris Nasus Larynx 2013;40:435-9. [CrossRef]

24. Fukushima K, Sugata K, Kasai N, Fukuda S, Nagayasu R, Toida N, et al. Better speech performance in cochlear implant patients with GBJ2-related deafness. Int J Pediatr Otorinolaryngol 2002;62:151-7. [CrossRef]

25. Connell SS, Angeli SI, Suarez H, Hodges AV, Balkany TJ, Liu HZ, et al. Performance after cochlear implantation in DFNB1 patients. Otolaryngol Head Neck Surgery 2007;137:596-602. [CrossRef]

26. Sinnathuray AR, Toner JG, Clarke-Lytlle J, Geddis A, Patterson CC, Hughs AE, et al. Connexin 26 (GBJ2) gene-related deafness and speech intelligibility after cochlear implantation. Otol Neurotol 2004;25:935-42. [CrossRef]

27. Chora JR, Matos TD, Martins JH, Alves MC, Andrade SM, Silva LF, et al. DFNB1-associared deafness in Portuguese cochlear implant users: prevalence and impact on oral communication. Int $J$ Pediatr Otorhinolaryngol 2010;74:1136-9. [CrossRef] 